\title{
Anatomic characteristics and dimensions of the nasopalatine canal: a radiographic study using cone-beam computed tomography
}

\author{
C. Görürgöz¹®i) B. Öztaş² \\ ${ }^{1}$ Department of Dentomaxillofacial Radiology, Bursa Uludağ University, Faculty of Dentistry, Bursa, Turkey \\ 2Department of Dentomaxillofacial Radiology, Ankara University, Faculty of Dentistry, Ankara, Turkey
}

[Received: 2 December 2019; Accepted: 11 December 2019; Early publication date: 23 September 2020]

Background: Description of the nasopalatine canal (NPC) is important for planning surgical treatment and comprehension of the morphology and pathogenesis of lesions that occur in the anterior maxilla. The goal of this study was to analyse the dimensions and anatomic characteristics of the NPC on cone-beam computed tomography (CBCT) scans, to determine the incidence of anatomical variation; and to assess the correlations of these variables with age, gender, and dental status. Materials and methods: A total of 320 individual CBCT images were included. Reformatted sagittal, coronal and axial slices were evaluated. Sagittal images were used for measurements of the NPC and to classified shape and direction-course of the NPC. Coronal images were used to analyse the NPC division levels and axial images were used to detect the number of palatal and nasal opening.

Results: The mean NPC length was $11.45 \pm 2.50 \mathrm{~mm}$; statistically significant differences were detected between males and females $(p<0.05)$. Mean nasopalatine angle was $76.26 \pm 8.12^{\circ}$; significant differences were detected in sagittal and coronal classifications. The most common canal was: funnel-shaped (29\%), slanted-curved direction-course (53.1\%), middle third division level (43.1\%), and one incisive foramen with two Stenson's foramina (1-2) (77.2\%).

Conclusions: The current study ensures new findings on the literature concerning the description of the anatomical structure of the canal. Also, the study highlights a significant variability in the anatomy and morphology of the NPC. Therefore, three-dimensional analysis of this structure is important for facilitating surgical management and preventing possible complications in this area. (Folia Morphol 2021; 80, 4: 923-934)

Key words: anatomy, cone-beam computed tomography, maxilla, nasopalatine canal, radiology

\section{INTRODUCTION}

The nasopalatine canal (NPC) is an important pathway between the nasal fossa and the palate, hence its name. It is also called the incisive canal since the NPC is located palatal to the central inci- sors [29]. In 1683, Stenson [24] made a complete description of the NPC for the first time. The NPC usually courses in the midline of the palate and behind the roots of central incisors. The opening of the NPC in the mouth is underneath the incisive 
papilla as incisive foramen (IF) and this canal ends in the nasal cavity through the nasal foramen as the Stensen's foramina (SF) $[12,19]$. The NPC contains the nasopalatine nerve and vessels, branches of the maxillary nerve, the maxillary artery [17] along with connective tissue, fat and minor salivary glands $[13,14]$.

Evaluation of morphological features and the morphometry of the NPC is especially important for preventing possible complications and planning many surgical treatments in the maxilla like apical surgery of central teeth, removal of the incisive duct cyst, dental implants, surgically-assisted rapid palatal expansion, dentoalveolar fractures, LeFort I osteotomy operations [9].

In recent years, some studies were published about the radiological morphology of the NPC on cone-beam computed tomography (CBCT) images, which are revealing considerable variation in the morphological characteristics of the canal $[1,5-7,10,21$, 26]. The present study aimed to a comprehensive evaluation of the radiological features of the canal in all three planes for relation to age, gender and dental status using $C B C T$ imaging and to create our relevant data on morphological characteristics of NPC which have received less attention or have not been defined still.

\section{MATERIALS AND METHODS}

The study sample consisted of CBCT images of 1,651 patients who referred to the Dentistry Faculty's Department of Dentomaxillofacial Radiology, between November 2016 and December 2017. CBCT examination of cases with several dentomaxillofacial problems such as impacted teeth, oral pathologies, orthognathic surgery, dental implants were retrospectively evaluated. Three hundred-twenty CBCT images were selected randomly. The protocol of the study was approved by local the Ethics Board of the Institution (Decision Number: 02/03. Clinical Trials Identifier: 36290600/08).

The inclusion criteria were: age $\geq 15$ years individuals; $C B C T$ images with sufficient diagnostic quality and imaging area. Patients with evidence of bone disease, dental trauma history, congenital abnormality, presence of impacted teeth, radiolucent or radiopaque pathologies, residual roots or dental implants, suspected NPC pathology (cyst), bone grafts and fixed orthodontic expansion devices were excluded from the final sample.

\section{CBCT imaging}

All CBCT scans were made in compliance with a standardised scanning protocol. CBCT images were obtained with Planmeca ProMax 3D Max (Helsinki, Finland with following parameters; $96 \mathrm{kVp}, 5.6-8 \mathrm{~mA}$, 9-12 s scan time, field of view $(50 \times 55 \mathrm{~mm}, 100 \times$ $\times 55 \mathrm{~mm}, 100 \times 90 \mathrm{~mm}, 130 \times 55 \mathrm{~mm}, 130 \times$ $\times 90 \mathrm{~mm}, 230 \times 160 \mathrm{~mm})$ and with two different voxel sizes $(200 \mu \mathrm{m}, 400 \mu \mathrm{m})$. All data were reconstructed at $0.5 \mathrm{~mm}$ slice interval and thickness.

\section{$\mathrm{CBCT}$ evaluations}

All the measurements and analysis were carried out by same oral radiologist on CBCT images, using Romexis 3.7 software programmes (Planmeca Oy, Helsinki, Finland) on a 21.3-inch flat-panel monitor (NEC MultiSync, Munchen, Germany) with $2048 \times$ $\times 2560$ pixel resolution, in a darkroom. The examiner could adjust the brightness and contrast of the images with the image-processing tool in the software to ensure ideal visual conditions for an accurate diagnosis. Before the evaluation, the three dimensions were calibrated and the three planes (sagittal, horizontal, and coronal) defined in each image.

\section{Measurements to detecting the dimensions of the NPC}

The following morphometric parameters, the width of the SF, IF and the length of the NPC were performed considering the protocol of Bornstein et al. [5]. The dimensions of the NPC (in $\mathrm{mm}$ ) and the canal angulation (in degrees) were estimated in the reformatted sagittal CBCT scans (Fig. 1): (1) The width $(\mathrm{mm})$ of the SF. If the canal had two or more nasal foramina, all visible SFs were added together; (2) The width $(\mathrm{mm})$ of the IF. If the canal had two or more palatal foramina, all visible IFs were added together; (3) The length $(\mathrm{mm})$ of the NPC. The length of the NPC was defined as the distance from mid-point of IF to the mid-point of SF; (4) The nasopalatine angle was defined as the intersection of the long axis of the canal and the palatal plane.

\section{Classifications of the variants in three planes}

In sagittal plane, the shapes of the canal were evaluated and classified into nine groups by adding two different types to the classification of Sekerci et al. [21]. In the literature, the type 4 canal shape which was only described in the study of Friedrich et al. [8] was added to the classification as "kink 


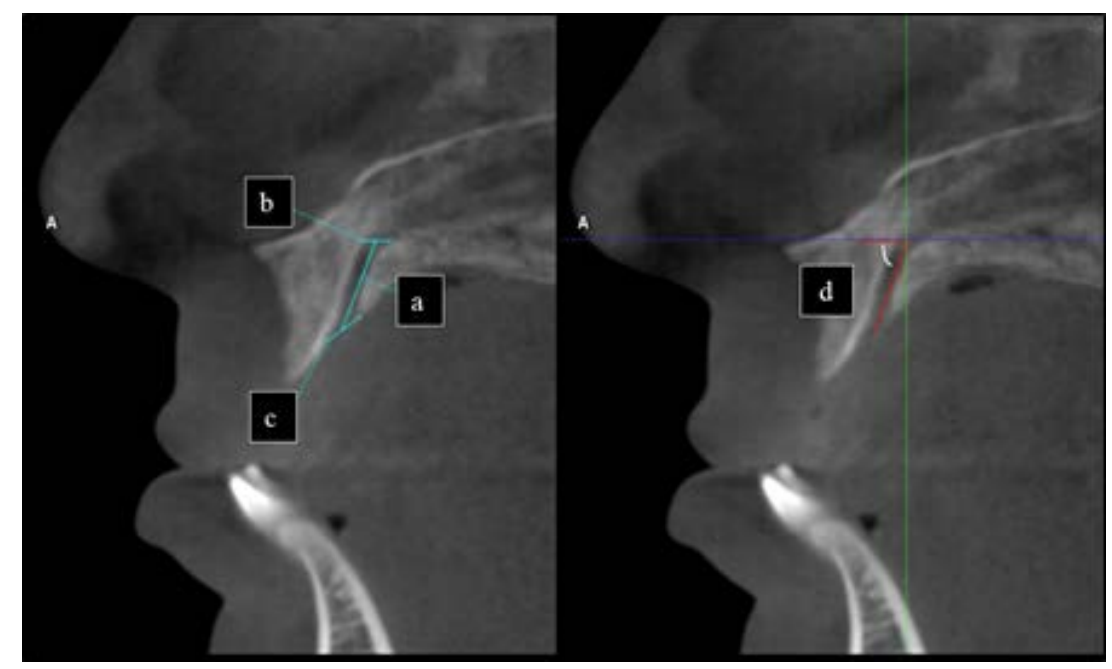

Figure 1. Measurements of anatomical structures in sagittal sections from cone-beam computed tomography image: the length of the nasopalatine canal (a); the diameter of the Stensen's foramina (b); the diameter of the incisive foramen (c); nasopalatine angle (d).

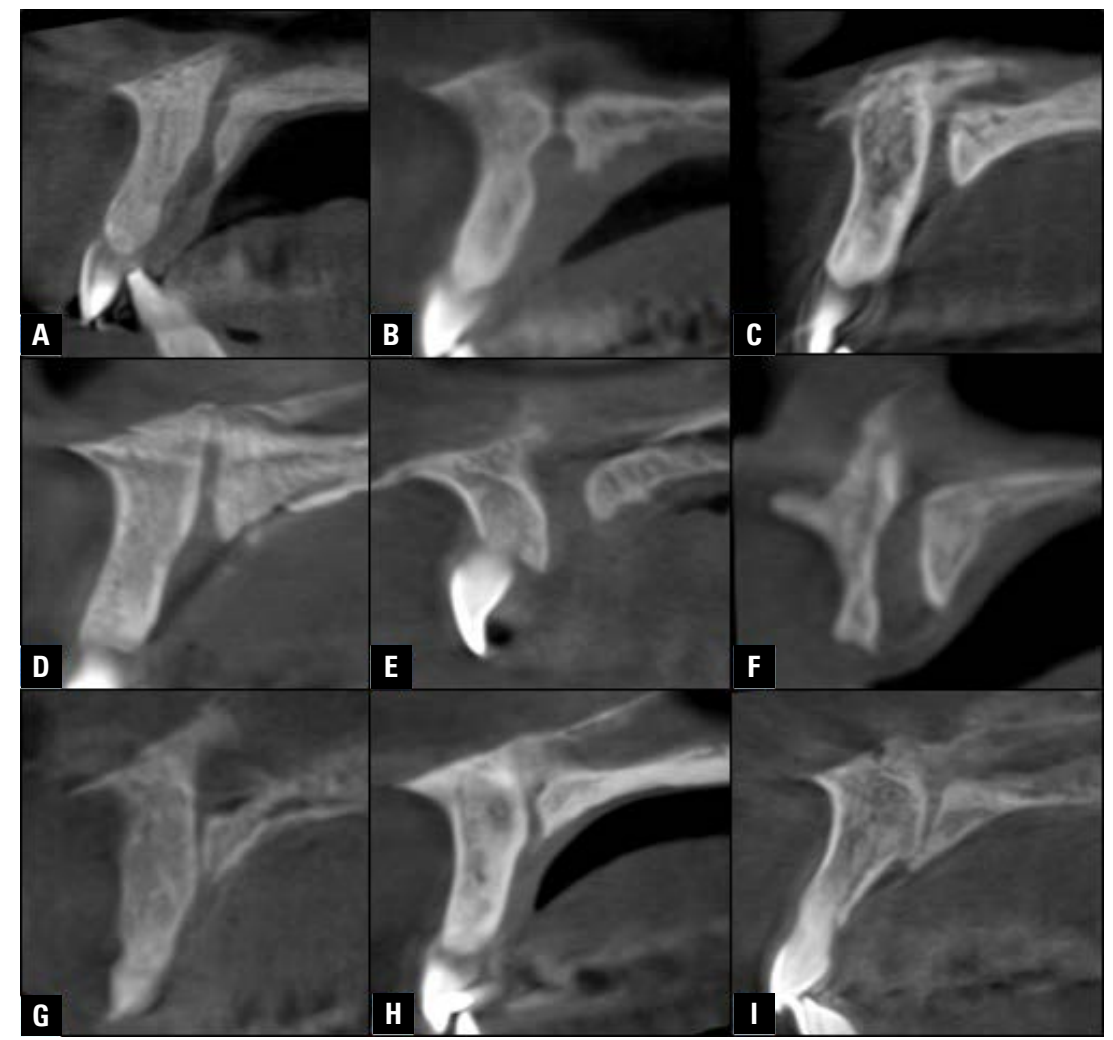

Figure 2. The nasopalatine canal shape classification in sagittal sections of cone-beam computed tomography images; A. Hourglass; B. Spindle; C. Cone; D. Funnel; E. Cylindrical; F. Banana; G. Tree branch; H. Kink; I. Other.

shape". In this group, this kinking was observed in the nasal or palatal third of the canal. The inverted cone shape is included in the cone group and the inverted funnel shape is included in the funnel group. The canal shapes that could not be included in these eight groups were classified under the title of "other". A total of nine groups were created: (1) hourglass, (2) spindle, (3) cone, (4) funnel, (5) banana, (6) cylindrical, (7) tree branch like, (8) kink, (9) other (Fig. 2). The NPC was also assessed concerning the classification of Song et al. [23] for its sagittal direction-course: (1) vertical-straight, (2) vertical-curved, (3) slanted-straight, (4) slanted-curved (Fig. 3). 

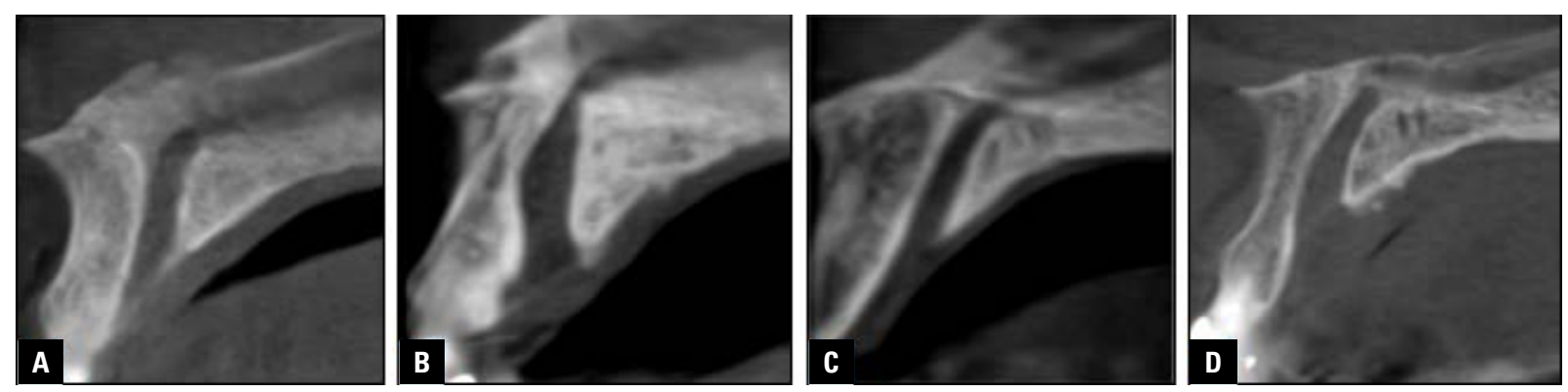

Figure 3. Direction-course of nasopalatine canal in sagittal slice; A. Vertical-straight canal; B. Vertical-curved canal; C. Slanted-straight canal; D. Slanted-curved canal.

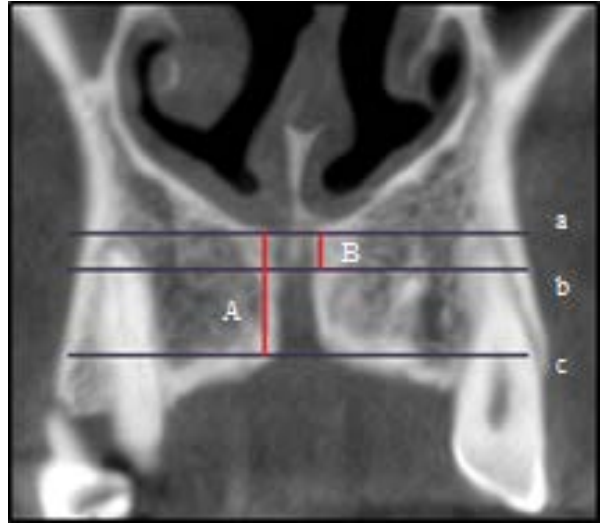

Figure 4. Cone-beam computed tomography frontal reconstruction showing the level of division of the nasopalatine canal (NPC), which is the ratio between the NPC coronal division length (B) and NPC coronal length (A); $a$ - NPC nasal level; $b$ - division plane level; C - NPC palate level.

In coronal plane, the NPC division levels were examined in the coronal slices based on the coronal ratio, that is the ratio of the canal length above the division to the entire length of the canal in the coronal plane (Fig. 4). The anatomic variants of the canal were classified into four groups [27]: (1) no division; (2) a division of the NPC in the upper-third level (coronal ratio < 0.33 ); (3) a division of the NPC in the middle-third level (coronal ratio of 0.66-0.33); (4) a division of the NPC in the lower-third level (coronal ratio of 1-0.65) (Fig. 5).

In axial plane, the variants of the canal were classified concerning the number of IFs (Fig. 6) and SF (Fig. 7). The axial groups were: 1-1, 1-2, 1-3, 1-4, 2-2, 3-2.

In addition, four groups were established according to dental status: group A - both central incisors present; group B - total edentulous individuals; group C - no central incisors present; group D - one central incisor present.
Finally, after an interval of 4 weeks, $20 \%$ of the 320 cases were selected randomly and measurements repeated by the same researcher to assess intra-observer variability.

\section{Statistical analysis}

Data analysis was performed using the IBM SPSS Statistics 21.0 (Statistical Package for Social Sciences) programme. The Shapiro-Wilk test was applied for evaluating compliance with the normal distribution of the data. The Student t-test and Kruskal-Wallis $\mathrm{H}$ test were performed for the comparison of two independent groups and three or more than groups, respectively. In addition, categorical variables were analysed using the $\chi^{2}$ test. The association between morphometric parameters and age was evaluated using the Spearman correlation coefficient. The $p$ value of less than 0.05 was considered significant.

\section{RESULTS}

The descriptive retrospective study subject comprised of 189 (59\%) females and 131 (41\%) males with an average age of $42.4 \pm 16.2$ (standard deviation [SD]) years (range 15-85 years).

The analysis of the sizes of the canal found out a mean width of the SF of $2.51 \pm 1.28 \mathrm{~mm}$ and a wider IF with a diameter of $5.29 \pm 1.37 \mathrm{~mm}$. The mean length of the canal was $11.45 \pm 2.50 \mathrm{~mm}$ and mean nasopalatine angle was $76.26 \pm 8.12^{\circ}$. The gender of the evaluated groups had a statistically significant effect on the length of the NPC and the width of IF, with the mean values tending to be greater for male subjects $(p<0.001)$. Males presented a wider SF diameter (mean $2.60 \mathrm{~mm}$ ) and nasopalatine angle (mean $77.11^{\circ}$ ) than females (mean $2.45 \mathrm{~mm}$, mean $75.68^{\circ}$, respectively) although no significant differences were found ( $p>0.05)$ (Table 1). 

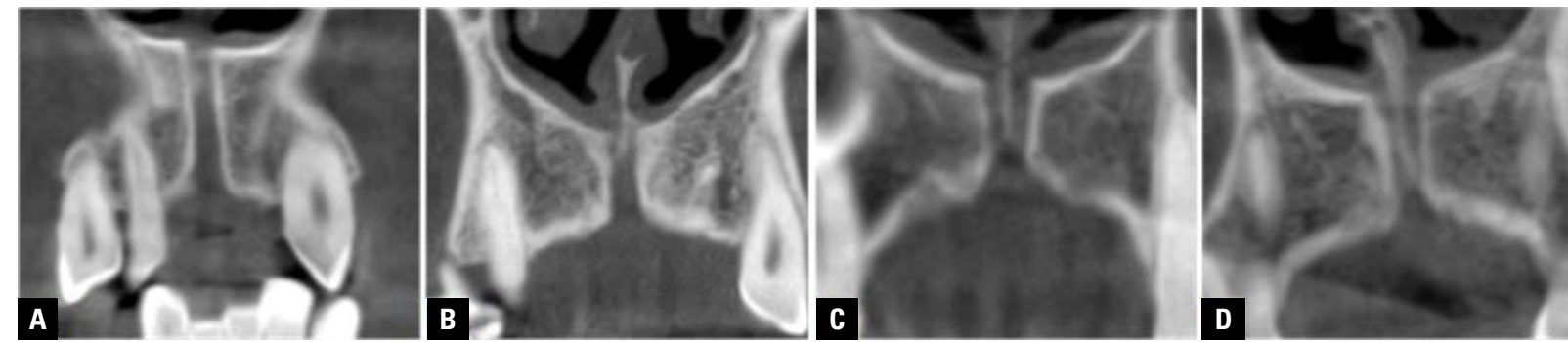

Figure 5. Division of the nasopalatine canal in coronal slice; A. No division; B. Upper-third level; C. Middle-third level; D. Lower-third level.

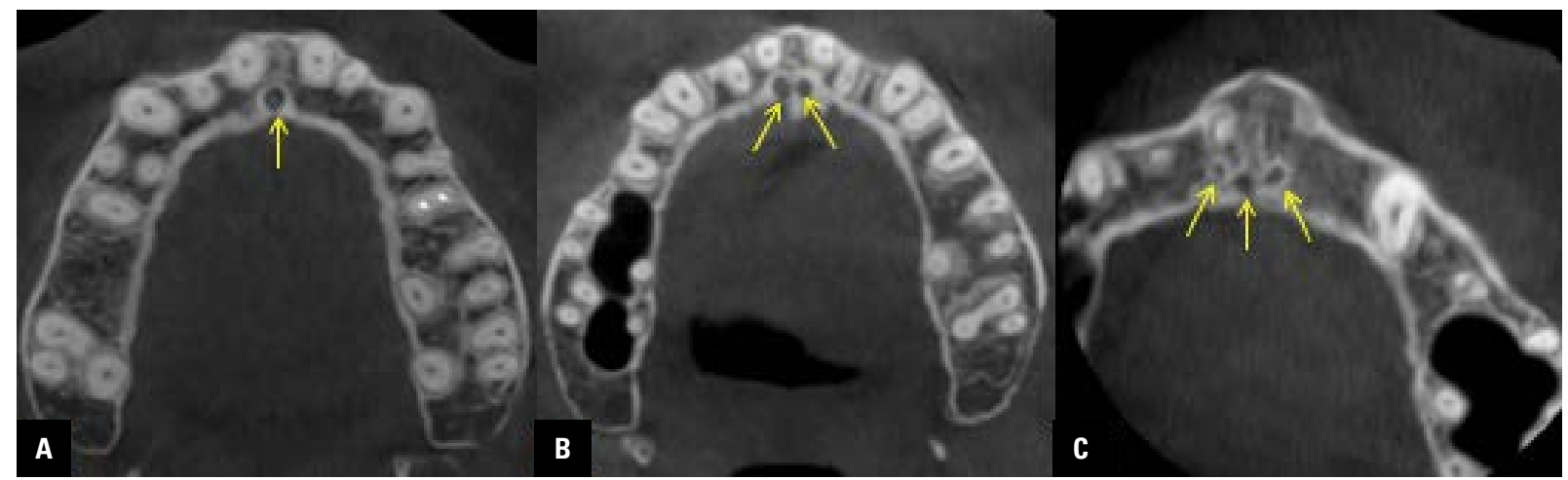

Figure 6. Axial images from cone-beam computed tomography scanner showing number of incisive foramina (IF); A. One IF; B. Two IFs; C. Three IFs (arrows).
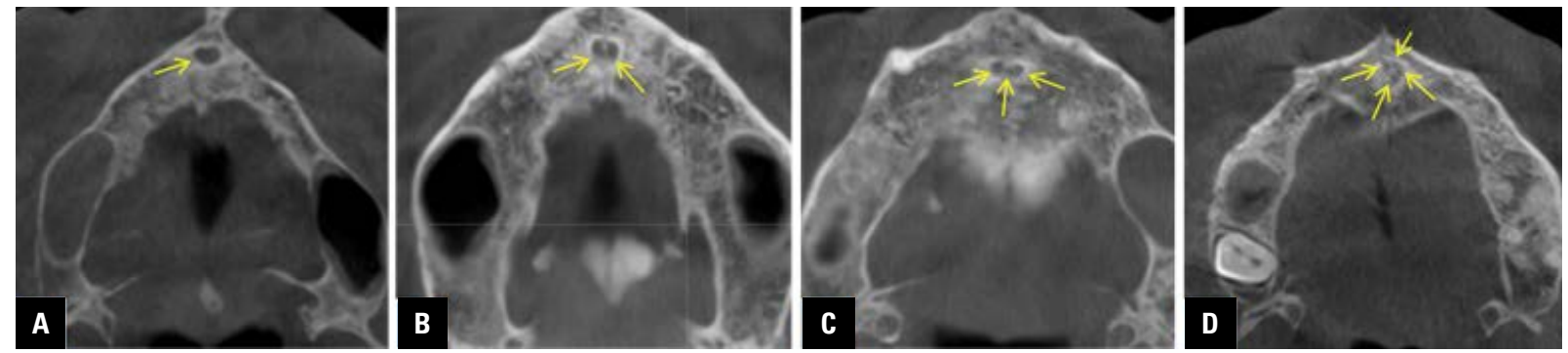

Figure 7. Axial images from cone-beam computed tomography scanner showing number of Stensen's foramina (SFs); A. One SF; B. Two SFs; C. Three SFs; D. Four SFs (arrows).

In sagittal plane, the most prevalent canal shape was found to be $93(29.1 \%)$ funnel-shaped, followed by hourglass-shaped in $52(16.3 \%)$ cases. Since the NPC shape $(3.1 \%)$ of 10 cases could not be included in this classification, they were examined under the title of "other". With respect to the sagittal shapes of canals, there was no significant difference between female and male $(p>0.05)$. The prevalences of NPC shapes according to sex are shown in Table 2.

In terms of the sagittal direction-course of NPC, the most common type was slanted-curved in 170 (53.1\%) cases, followed by vertical-curved in 67 (20.9\%) cases, slanted-straight in $48(15 \%)$ cases, and vertical-straight in $35(10.9 \%)$ cases (Table 2$)$. The slanted type was detected more frequently $(218,68.12 \%)$ than the vertical type $(102,31.88 \%)$. The sagittal direction and course of the canal revealed no significant difference between genders $(p=0.685)$ (Table 2$)$.

The NPC length results for kink-shaped and coneshaped groups were significantly lower than other groups $(p<0.05)$. The width of the SF in the funnel-shaped was significantly narrow than the other groups $(p<0.05)$. No statistically significant correlations were detected with respect to the sagittal shape of the canal and the diameter of the IF and nasopalatine angle (Table 3 ). 
Table 1. Analysis effect of gender on the dimensions (in $\mathrm{mm}$ ) of the nasopalatine canal, using reformatted sagittal slices from cone -beam computed tomography images

\begin{tabular}{|c|c|c|c|c|c|c|c|c|c|c|c|c|c|}
\hline & \multicolumn{4}{|c|}{ Male } & \multicolumn{4}{|c|}{ Female } & \multicolumn{4}{|c|}{ Total } & \multirow[t]{2}{*}{$\mathbf{P}$} \\
\hline & Min & Max & Mean & SD & Min & Max & Mean & SD & Min & Max & Mean & SD & \\
\hline$a$ & 6.28 & 19.22 & 12.46 & 2.46 & 5.20 & 18.22 & 10.74 & 2.27 & 5.20 & 19.92 & 11.45 & 2.5 & $0,0001^{*}$ \\
\hline b & 0.40 & 7.11 & 2.6 & 1.39 & 0.4 & 8 & 2.45 & 1.19 & 0.40 & 8 & 2.51 & 1.28 & 0,306 \\
\hline$c$ & 1.72 & 9.4 & 5.63 & 1.35 & 1.56 & 10.47 & 5.06 & 1.34 & 1.56 & 10.47 & 5.29 & 1.37 & $0,0001^{*}$ \\
\hline$d$ & 60.26 & 104.58 & 77.11 & 8.03 & 58.52 & 99.92 & 75.68 & 8.16 & 58.52 & 104.58 & 76.26 & 8.12 & 0,121 \\
\hline
\end{tabular}

${ }^{*}$ Statistically significant differences $(p<0.05)$, min — minimum; max - maximum; SD — standard deviation. Measurements a-d correspond to distances shown in Figure 1

Table 2. Nasopalatine canal shape distributions by gender

\begin{tabular}{|c|c|c|c|c|c|c|c|c|}
\hline \multirow{2}{*}{$\begin{array}{l}\text { Nasopalatine canal } \\
\text { classifications }\end{array}$} & & \multicolumn{2}{|c|}{ Male } & \multicolumn{2}{|c|}{ Female } & \multicolumn{2}{|c|}{ Total } & \multirow[t]{2}{*}{$\mathbf{P}$} \\
\hline & & $\mathbf{N}$ & $\%$ & $\mathbf{N}$ & $\%$ & $\mathbf{N}$ & $\%$ & \\
\hline \multirow[t]{9}{*}{ Sagittal variation/sagittal shape } & Hourglass & 24 & 18.3 & 28 & 14.8 & 52 & 16.3 & 0.704 \\
\hline & Spindle & 3 & 2.3 & 9 & 4.8 & 12 & 3.8 & \\
\hline & Cone & 13 & 9.9 & 23 & 12.2 & 36 & 11.6 & \\
\hline & Funnel & 38 & 29. & 55 & 29.1 & 93 & 29.1 & \\
\hline & Banana & 10 & 7.6 & 17 & 9 & 27 & 8.4 & \\
\hline & Cylindrical & 19 & 14.5 & 30 & 15.9 & 49 & 15.3 & \\
\hline & Tree branch like & 10 & 7.6 & 7 & 3.7 & 17 & 5.3 & \\
\hline & Kinking shape & 11 & 8.4 & 13 & 6.9 & 24 & 6 & \\
\hline & Other & 3 & 2.3 & 7 & 3.7 & 10 & 3.1 & \\
\hline \multirow[t]{4}{*}{ Sagittal direction-course } & Vertical-straight & 21 & 11.1 & 14 & 10.7 & 35 & 10.9 & 0.685 \\
\hline & Vertical-curved & 39 & 20.6 & 28 & 21.4 & 67 & 20.9 & \\
\hline & Slanted-straight & 32 & 16.9 & 16 & 12.2 & 48 & 15 & \\
\hline & Slanted-curved & 97 & 51.3 & 73 & 55.7 & 170 & 53.1 & \\
\hline
\end{tabular}

*Statistically significant differences $(p<0.05), N-$ number of subjects

The NPC length was significantly higher in the slanted-curved canal groups than other groups $(p=0.005)$. The SF diameter values were significantly higher in the vertical-straight canal group than other groups $(p=0.015)$. The IF diameters were significantly lower in the vertical-curved canal groups compared to the slanted-curved and the vertical-straight canal groups $(p=0.042)$. The nasopalatine angle was significantly wider in the vertical type than the slanted type $(p<0.05)$ (Table 4$)$.

In coronal plane, the division of the canal was assessed. The middle-third level was the most frequent with $138(43.1 \%)$ cases, followed by the upper-third level in $90(28.1 \%)$ cases, and the lower-third level in $54(16.9 \%)$ cases. In 38 cases, no divisions were observed during the course of the NPC. No significant difference was found between the presence of division in the NPC and gender $(p>0.05)$ but, there was a statistically significant relationship between division level of the canal and gender $(p=0.006)$. The NPC division in the middle-third level was the most common in males, while in females the most prevalent division levels of NPC were detected as upper-third and lower-third level. However, the same could not be detected for age groups. Also, the effect of the division in the canal on the measurements in the NPC was presented in Table 5.

In axial plane, the prevalences of incisive foramina were the following: $98.4 \%$ of the individuals had single IF, while $1.3 \%$ had double IFs and only 1 case had triple IFs. Results for the number of foramina of Stenson: the most common opening was double SFs with 252 (78.8\%) individuals, single SF was observed in $41(12.8 \%)$ individuals, triple SFs in $23(7.2 \%)$ individuals, and quadruple SFs in $4(1.3 \%)$ individuals. Also, the most prevalent axial group was "1-2" in $247(77.2 \%)$ cases, meanwhile " $3-2$ " axial group was observed in only $1(0.3 \%)$ case (Table 6$)$.

The findings regarding total distribution of dental status are shown in Table 7. With respect to the existence of central incisors, there was no significant difference 
Table 3. Effect of sagittal shape of the canal on nasopalatine canal dimensions

\begin{tabular}{|c|c|c|c|c|c|c|}
\hline Parameters & Sagittal shape & $\mathbf{N}$ & Mean & SD & H & $\mathbf{P}$ \\
\hline \multirow[t]{9}{*}{ Nasopalatine canal length [mm] } & Hourglass & 52 & 11.38 & 2.35 & 25.4 & $0.001^{*}$ \\
\hline & Spindle & 12 & 11.20 & 2.56 & & \\
\hline & Cone & 36 & 10.69 & 2.05 & & \\
\hline & Funnel & 93 & 12.22 & 2.53 & & \\
\hline & Banana & 27 & 11.20 & 2.54 & & \\
\hline & Cylindrical & 49 & 10.83 & 2.35 & & \\
\hline & Tree branch like & 17 & 11.75 & 2.37 & & \\
\hline & Kinking shape & 24 & 10.47 & 2.88 & & \\
\hline & Other & 10 & 13.19 & 1.91 & & \\
\hline \multirow[t]{9}{*}{ Foramina of Stenson diameter [mm] } & Hourglass & 52 & 3.03 & 1.14 & 65.6 & $0.0001^{*}$ \\
\hline & Spindle & 12 & 2.30 & 1 & & \\
\hline & Cone & 36 & 2.23 & 1.02 & & \\
\hline & Funnel & 93 & 1.81 & 1.06 & & \\
\hline & Banana & 27 & 2.95 & 1.51 & & \\
\hline & Cylindrical & 49 & 3.08 & 1.21 & & \\
\hline & Tree branch like & 17 & 2.36 & 1.49 & & \\
\hline & Kinking shape & 24 & 3.15 & 1.18 & & \\
\hline & Other & 10 & 2.19 & 1.14 & & \\
\hline \multirow[t]{9}{*}{ Incisive foramina diameter [mm] } & Hourglass & 52 & 5.56 & 1.29 & 8.1 & 0.424 \\
\hline & Spindle & 12 & 5.52 & 1.42 & & \\
\hline & Cone & 36 & 5.54 & 1.11 & & \\
\hline & Funnel & 93 & 5.25 & 1.44 & & \\
\hline & Banana & 27 & 4.99 & 1.43 & & \\
\hline & Cylindrical & 49 & 5.13 & 1.38 & & \\
\hline & Tree branch like & 17 & 5.07 & 1.44 & & \\
\hline & Kinking shape & 24 & 5.09 & 1.29 & & \\
\hline & Other & 10 & 5.54 & 1.94 & & \\
\hline \multirow[t]{9}{*}{ Nasopalatine angle $\left[^{\circ}\right]$} & Hourglass & 52 & 76.03 & 7.78 & 6.6 & 0.576 \\
\hline & Spindle & 12 & 78.03 & 10.58 & & \\
\hline & Cone & 36 & 77.11 & 7.26 & & \\
\hline & Funnel & 93 & 75.65 & 7.72 & & \\
\hline & Banana & 27 & 78.90 & 9.25 & & \\
\hline & Cylindrical & 49 & 76.47 & 9.19 & & \\
\hline & Tree branch like & 17 & 77.15 & 8.59 & & \\
\hline & Kinking shape & 24 & 74.40 & 6.95 & & \\
\hline & Other & 10 & 72.79 & 6.11 & & \\
\hline
\end{tabular}

${ }^{*}$ Statistically significant differences $(\mathrm{p}<0.05), \mathrm{SD}$ - standard deviation; $\mathrm{N}$ - number of subjects

between genders. However, statistically, a significant correlation was found among age and presence of central incisors. The age of Group B was older than the other groups $(p=0.001)$. Also, dental status had no statistically important influence on the variations and morphometric measurements of the NPC $(p>0.05)$.
Statistically, no significant correlation was detected among age and length of the NPC, SF width, and the nasopalatine angle $(p=0.23, p=0.114$, $p=0.098$, respectively) (Table 8 ). However, there is a weak, positive and statistically significant relationship between age and the width of IF was detected. 
Table 4. Effect of sagittal direction-course of the nasopalatine canal dimensions, nasopalatine angle and nasopalatine canal length

\begin{tabular}{|c|c|c|c|c|c|c|}
\hline Parameters & Sagittal direction-course & $\mathbf{N}$ & Mean & SD & H & $\mathbf{P}$ \\
\hline \multirow[t]{4}{*}{ Nasopalatine canal length [mm] } & Vertical-straight & 35 & 11.12 & 2.50 & 12.6 & $0.005^{*}$ \\
\hline & Vertica-curved & 67 & 10.89 & 2.35 & & \\
\hline & Slanted-straight & 48 & 10.74 & 2.22 & & \\
\hline & Slanted-curved & 170 & 11.93 & 2.54 & & \\
\hline \multirow[t]{4}{*}{ Foramina of Stenson diameter [mm] } & Vertical-straight & 35 & 3.14 & 1.38 & 10.4 & $0.015^{*}$ \\
\hline & Vertical-curved & 67 & 2.39 & 1.42 & & \\
\hline & Slanted-straight & 48 & 2.50 & 1.14 & & \\
\hline & Slanted-curved & 170 & 2.43 & 1.20 & & \\
\hline \multirow[t]{4}{*}{ Incisive foramina diameter [mm] } & Vertical-straight & 35 & 5.38 & 1.09 & 8.2 & $0.042^{*}$ \\
\hline & Vertical-curved & 67 & 4.97 & 1.61 & & \\
\hline & Slanted-straight & 48 & 5.11 & 1.49 & & \\
\hline & Slanted-curved & 170 & 5.45 & 1.27 & & \\
\hline \multirow[t]{4}{*}{ Nasopalatine angle $\left[{ }^{0}\right]$} & Vertical-straight & 35 & 85.58 & 4.92 & 203.1 & $0.0001^{*}$ \\
\hline & Vertical-curved & 67 & 85.10 & 3.80 & & \\
\hline & Slanted-straight & 48 & 72.44 & 4.84 & & \\
\hline & Slanted-curved & 170 & 71.94 & 5.98 & & \\
\hline
\end{tabular}

${ }^{*}$ Statistically significant differences $(p<0.05), S D$ - standard deviation; $N$ - number of subjects

Table 5. Effect of the division of the canal on nasopalatine canal dimensions

\begin{tabular}{|c|c|c|c|c|c|c|}
\hline Parameters & Division & $\mathbf{N}$ & Mean & SD & H & $\mathbf{P}$ \\
\hline \multirow[t]{4}{*}{ Nasopalatine canal length [mm] } & No division & 38 & 11.70 & 2.55 & 20.4 & $0.0001^{*}$ \\
\hline & Upper third level & 90 & 11.71 & 2.62 & & \\
\hline & Middle third level & 138 & 11.73 & 2.29 & & \\
\hline & Lower third level & 54 & 10.11 & 2.39 & & \\
\hline \multirow[t]{4}{*}{ Foramina of Stenson diameter [mm] } & No division & 38 & 2.07 & 1.31 & 10.2 & $0.016^{*}$ \\
\hline & Upper third level & 90 & 2.33 & 1.18 & & \\
\hline & Middle third level & 138 & 2.62 & 1.28 & & \\
\hline & Lower third level & 54 & 2.81 & 1.31 & & \\
\hline \multirow[t]{4}{*}{ Incisive foramina diameter [mm] } & No division & 38 & 5.44 & 1.23 & 7.8 & $0.049 *$ \\
\hline & Upper third level & 90 & 5.19 & 1.44 & & \\
\hline & Middle third level & 138 & 5.47 & 1.24 & & \\
\hline & Lower third level & 54 & 4.90 & 1.60 & & \\
\hline \multirow[t]{4}{*}{ Nasopalatine angle $\left[{ }^{\circ}\right]$} & No division & 38 & 73.69 & 8.44 & 3.9 & 0.272 \\
\hline & Upper third level & 90 & 76.67 & 8.11 & & \\
\hline & Middle third level & 138 & 76.43 & 7.61 & & \\
\hline & Lower third level & 54 & 76.98 & 9.05 & & \\
\hline
\end{tabular}

*Statistically significant differences $(\mathrm{p}<0.05), \mathrm{SD}$ - standard deviation; $\mathrm{N}$ - number of subjects

\section{Intraobserver consistency}

The Cohen's kappa, weighted kappa statistic, and intra-class correlation (ICC) were performed to evaluate the observer's agreement. An excellent agreement was indicated between the first and second measure- ments and figural analysis: ICC $=0.790(p<0.001)$ for diameter SF; ICC $=0.877$ ( $p<0.001)$ for diameter IF, and ICC $=0.944(p<0.001)$ for length of NPC; KW $=0.963(p<0.001)$ for shape of the NPC. 
Table 6. The distribution of the nasopalatine canal morphology

\begin{tabular}{|c|c|c|c|c|c|c|c|c|}
\hline & & \multicolumn{2}{|c|}{ Male } & \multicolumn{2}{|c|}{ Female } & \multicolumn{2}{|c|}{ Total } & \multirow[t]{2}{*}{$\mathbf{P}$} \\
\hline & & $\mathbf{N}$ & $\%$ & $\mathbf{N}$ & $\%$ & $\mathbf{N}$ & $\%$ & \\
\hline \multirow[t]{4}{*}{ Number of Stensen's foramina } & 1 & 13 & 9.9 & 28 & 14.8 & 41 & 12.8 & 0.457 \\
\hline & 2 & 104 & 79.4 & 148 & 78.3 & 252 & 78.8 & \\
\hline & 3 & 12 & 9.2 & 11 & 5.8 & 23 & 7.2 & \\
\hline & 4 & 2 & 1.5 & 2 & 1.1 & 4 & 1.3 & \\
\hline \multirow[t]{3}{*}{ Number of incisive foramen } & 1 & 130 & 99.2 & 185 & 97.9 & 315 & 98.4 & 0.792 \\
\hline & 2 & 1 & 0.8 & 3 & 1.6 & 4 & 1.3 & \\
\hline & 3 & 0 & 0.0 & 1 & 0.5 & 1 & 0.3 & \\
\hline \multirow[t]{6}{*}{ Axial group } & $1-1$ & 13 & 9.9 & 28 & 14.8 & 41 & 12.8 & 0.604 \\
\hline & $1-2$ & 103 & 78.6 & 144 & 76.2 & 247 & 77.2 & \\
\hline & $1-3$ & 12 & 9.2 & 11 & 5.8 & 23 & 7.2 & \\
\hline & $1-4$ & 2 & 1.5 & 2 & 1.1 & 4 & 1.3 & \\
\hline & $2-2$ & 1 & 0.8 & 3 & 1.6 & 4 & 1.3 & \\
\hline & $3-2$ & 0 & 0.0 & 1 & 0.5 & 1 & 0.3 & \\
\hline
\end{tabular}

${ }^{*}$ Statistically significant differences $(\mathrm{p}<0.05), \mathrm{N}-$ number of subjects

Table 7. Results of dimensional comparison of nasopalatine canal measurements according to edentulous status

\begin{tabular}{|c|c|c|c|c|c|c|}
\hline $\begin{array}{l}\text { Edentulous } \\
\text { status }\end{array}$ & $\mathbf{N}$ & $\begin{array}{l}\text { Mean length of nasopalatine } \\
\text { canal } \pm \text { SD }[\mathrm{mm}]\end{array}$ & $\begin{array}{l}\text { Mean diameter of Stenson's } \\
\text { foramina } \pm S D[\mathrm{~mm}]\end{array}$ & $\begin{array}{l}\text { Mean diameter of incisive } \\
\text { foramen } \pm \text { SD [mm] }\end{array}$ & $\begin{array}{c}\text { Mean nasopalatine } \\
\text { angle } \pm S D\left[^{\circ}\right]\end{array}$ & $\mathbf{P}$ \\
\hline Group A & 251 & $11.47 \pm 2.46$ & $2.55 \pm 1.29$ & $5.24 \pm 1.33$ & $76.12 \pm 8.38$ & 0.666 \\
\hline Group B & 25 & $11.63 \pm 2.40$ & $2.13 \pm 1.00$ & $5.76 \pm 1.53$ & $78.03 \pm 7.85$ & 0.701 \\
\hline Group C & 26 & $10.95 \pm 2.65$ & $2.53 \pm 1.51$ & $5.63 \pm 1.30$ & $75.58 \pm 6.41$ & 0.055 \\
\hline Group D & 18 & $11.59 \pm 3.05$ & $2.41 \pm 0.98$ & $4.91 \pm 1.76$ & $76.79 \pm 7.30$ & 0.602 \\
\hline
\end{tabular}

${ }^{*}$ Statistically significant differences $(\mathrm{p}<0.05)$, SD — standard deviation; $\mathrm{N}$ - number of subjects

Table 8. Correlation between nasopalatine canal measurements and patient age

\begin{tabular}{ccccc}
\hline Correlation coefficients & Nasopalatine canal length & Foramina of Stenson diameter & Incisive foramen diameter & Nasopalatine angle \\
\hline Age & & & & -0.093 \\
$r$ & 0.067 & -0.089 & $0.158^{* *}$ & 0.098 \\
$\mathrm{p}$ & 0.23 & 0.114 & 0.005 & \\
\hline
\end{tabular}

$r<0.01$ is statistically significant, $p<0.05$ is statistically significant

\section{DISCUSSION}

Radiologic imaging is an important diagnostic instrument for surgical procedures and post-operative assessment in today's surgical approach. Description of the variations, particularly involving neurovascular anatomy, plays a significant role in surgical process. The neurovascular content in the premaxilla increases the risk of complications in this region [21].

Conventional imaging methods do not have adequate confidence in the assessment of neurovascular structures in bone [3, 25]. Various imaging techniques were used in other presented studies about the NPC.
CT images [14, 16, 17], micro-CT scans [23] or magnetic resonance imaging [12] have been used in the previously to evaluate the macro and micro-anatomy of the premaxilla and also the neurovascular bundle of the NPC. In the current study, the NPC was analysed with $\mathrm{CBCT}$ for three-dimensional evaluation. More recently, CBCT has been accepted as an alternative imaging modality for assessment of the neurovascular content and bone in the anterior maxillary region compared using by CT due to higher spatial resolution, substantially lower radiation dose, low cost, easy access and increased use [15]. 


\section{Measurements}

In some studies, the IF was estimated by a line parallel to the transverse plane [17]. The authors suggest that using this technique would have resulted in a shorter NPC length than its exact size and the narrower width for IF. So, in the current research in which dimensional assessments of the canal were performed using the Bornstein et al. [5] method, the average length of the NPC was found to be $11.45 \mathrm{~mm}$. In the literature, the mean length of NPC has been reported to be between $8.1 \mathrm{~mm}$ and $16.33 \mathrm{~mm}[16,28]$. Bornstein et al. [5], Ozcakir-Tomruk et al. [18], Tözüm et al. [28], and Sekerci et al. [21] indicated similar mean values at $10.99 \mathrm{~mm}, 10.87 \mathrm{~mm}, 10.86 \mathrm{~mm}$, and $10.8 \mathrm{~mm}$, respectively, but Mraiwa et al. [17] and Liang et al. [14] reported a lower canal lengths.

No significant correlation was observed between patient ages and length of the canal. Therefore it can be speculated that NPC length differences among studies are not owing to the mean age of the samples, but may result from the method used, scanning techniques, ethnic differences or variations in gender distribution of the samples [18]. Furthermore, Bajoria et al. [4], although they found statistically significant results $(p=0.0001)$ in different age groups with length of NPC, they stated that this difference might be due to dental status rather than age-related changes. Mardinger et al. [16] have concluded that the canal was not a static formation that tended to expanded in all dimensions after tooth extractions and aging. Thus, the edentulous group might be older than the dentate group, so the morphological differences according to the dental status related to not only teeth existence but also age-related changes in bone quantity and quality.

In terms of dental status, our findings were unlike other researches that noted significantly longer canal length in the dentulous group $[6,14,18]$. In the current study, NPC length was shortest in group B (total edentulous individuals) which was not statistically significant. In addition, statistically significant differences were not observed between the width of the IF and SF according to the dental status. These results are consistent with the conclusions of Liang et al. [14] and Tözüm et al. [28].

It is generally believed that the diameter of the IF is less than $6 \mathrm{~mm}$ and when it exceeds $10 \mathrm{~mm}$ pathological risks should be considered [17]. In this study, the IF stayed under this cut-off value (mean
$5.29 \mathrm{~mm}$ ), but the width between 1.56 to $10.47 \mathrm{~mm}$, even no presence of NPC pathology.

Although there was the difference between one of the reference points used by these researchers [14] and our study (while our reference plane was the nasal floor, some of them used the horizontal plane of the palate), both planes are parallel and comparisons can be made. In the present study, no correlation was found between the length of NPC and the nasopalatine angle.

\section{The variations of the NPC}

In this study, all three planes were taken into consideration to make a detailed anatomical analysis.

In sagittal plane. In the literature, studies about the variations of the shape of the canal have been reported, but standard classification was not found. Fernandez-Alonso et al. [7] and Gönül et al. [9] classified the shape of the canal in four groups (hourglass, cylindrical, funnel, banana) in sagittal planes, but Liang et al. [14] divided into only two groups: conical and cylindrical. Sekerci et al. [21], Etoz and Şişman [6] and Hakbilen and Magat [11] evaluated the shape of the canal in six groups (hourglass, cone, funnel, cylinder, banana and tree branches) in their studies. However, these classifications were inadequate to fully evaluate the shape of the NPC. All canal shapes defined in the literature were analysed and a new classification was made. It was detected that, while the funnel shapes (29.1\%) and hourglass shapes (16.3\%) were found at the highest rate, the rate of the spindle shapes and "other" groups were seen at the lowest rated, respectively 3.8\%, 3.1\%. These results are consistent with most studies in the literature $[4,6,11,20,21,26]$. However, the results are different from studies presented by Tözüm et al. [28], Hakbilen and Magat [11] and Gönül et al. [9]. We suggest that these variations may come out from racial characteristics, the number of samples and distinctions between classifications.

Our results for sagittal direction-course are contrary to Song et al. [23] who found the majority of the vertical type of the canal, but in this study, slanted ones were more frequent than vertical types. Also, the present results for the straight canal versus curved canal types were different from these researchers. It can be owing to the less sample number in their study [23].

Which was analysed in only one study previously, we presented differences in the NPC angle with re- 
spect to the direction and course [7]. In the present study, it is shown that the angle results of the vertical types were greater than those of the slanted types. This finding is consistent with the results of Fernandez-Alonso et al. [7].

The shape, direction and course of the canal with the NPC angle should be considered for the location and angulation of dental implants [7]. Liang et al. [14] point out that the contact of dental implants with neural tissue may affect the osseointegration of the implant.

In coronal plane. Since the shape of the canal may change due to the divisions within the canal between the coronal sections, only the presence and level of the division were evaluated in this plane, unlike previous studies $[5-9,18,21]$.

In the literature, only 3 studies are examining the division classification of the NPC $[20,26,27]$. Thakur et al. [26] and Safi et al. [20] mentioned the division at the middle third as the most frequent form, respectively $51 \%, 51.5 \%$ were found in the upper third. These findings were compatible with the present study.

While not analysed by previous studies, divisions within the canal affect the diameters and length of the canal. Regarding coronal slice, the NPC length and width of IF were significantly lower in the lower-third level group than other groups $(p<0.05)$. However, the width of SF was greater in the lower-third level group. In addition, no significant difference was found between division groups and the NPC angle ( $p>0.05)$.

In axial plane. In the literature, NPC was classified according to the numbers in the axial plane on $\mathrm{CBCT}$ images. Most variations of the NPC reported at the level of the nasal floor. Some of the studies classified nasopalatine foramina in four groups $[6,8,14,26,27]$ while some of them evaluated in three groups $[4,21]$ on the axial section. However, they did not give any information about the number of incisive foramina. Also, Sicher [22] found that nasal opening might be present from a single foramen and up to six separate foramina. Besides, in contrast to common belief, Al-Amery et al. [1] and Song et al. [23] evaluated the NPC at the middle portion to the level of the nasal opening. In this study, the number of openings of the canal in the nasal and palatal level detected and these levels were evaluated together for established the axial classification.

In terms of axial classification, the most often axial group in the current study was "1-2" (in $77.2 \%$ of individuals). The result was consistent with the literature $[8,9]$. However, Liang et al. [14] reported that " $1-1$ " to be the most frequent group (44\%), followed by "1-2" (39\%).

In this study, no significant difference was found in the morphology of the canal between the dental groups. It may result from the interindividual variations and non-homogenous distribution of dental groups. Also, the rate of resorption can change inter-individual and even in the same individual at different times [2]. The time span since tooth loss and factors (anatomic, metabolic, functional, and prosthetic factors) which affect the rate of resorption should be taken into consideration in future studies.

\section{CONCLUSIONS}

Rehabilitation of the anterior maxilla is with high clinical relevance in relation to function and aesthetic. New findings are reported in this study, about the classification of the canal shape and differences in morphometric measurements with respect to the level of the division. The present results emphasized the variability of the NPC in terms of several parameters; therefore, the authors recommend an improved understanding of this anatomic structure and using cross-sectional imaging for better surgical results and to reduce surgical complications.

\section{Acknowledgements}

This study was presented as an oral presentation in TDA $25^{\text {th }}$ International Dental Congress, 4-7 September 2019, Istanbul, Turkey.

\section{Conflict of interest: None declared}

\section{REFERENCES}

1. Al-Amery SM, Nambiar P, Jamaludin $M$, et al. Cone beam computed tomography assessment of the maxillary incisive canal and foramen: considerations of anatomical variations when placing immediate implants. PLoS One. 2015; 10(2): e0117251, doi: 10.1371/journal.pone.0117251, indexed in Pubmed: 25679505.

2. Asaumi R, Kawai T, Sato l, et al. Three-dimensional observations of the incisive canal and the surrounding bone using cone-beam computed tomography. Oral Radiology. 2010; 26(1): 20-28, doi: 10.1007/s11282-010-0039-4.

3. Bahşi I, Orhan M, Kervancıoğlu P, et al. Anatomical evaluation of nasopalatine canal on cone beam computed tomography images. Folia Morphol. 2019; 78(1): 153-162, doi: 10.5603/FM.a2018.0062, indexed in Pubmed: 30009362.

4. Bajoria A, Kochar T, Sangamesh NC, et al. Nasopalatine canal revisited: an insight to anterior maxillary implants. 
Open J Stomatol. 2018; 08(01): 1-15, doi: 10.4236/ ojst.2018.81001.

5. Bornstein $M M$, Balsiger $R$, Sendi $P$, et al. Morphology of the nasopalatine canal and dental implant surgery: a radiographic analysis of 100 consecutive patients using limited cone-beam computed tomography. Clin Oral Implants Res. 2011; 22(3): 295-301, doi: 10.1111/j.16000501.2010.02010.x, indexed in Pubmed: 21039896.

6. Etoz M, Sisman Y. Evaluation of the nasopalatine canal and variations with cone-beam computed tomography. Surg Radiol Anat. 2014; 36(8): 805-812, doi: 10.1007/s00276014-1259-9, indexed in Pubmed: 24488202.

7. Fernández-Alonso A, Suárez-Quintanilla JA, Muinelo-Lorenzo J, et al. Three-dimensional study of nasopalatine canal morphology: a descriptive retrospective analysis using cone-beam computed tomography. Surg Radiol Anat. 2014; 36(9): 895-905, doi: 10.1007/s00276-014-1297-3, indexed in Pubmed: 24752396.

8. Friedrich RE, Laumann F, Zrnc T, et al. The nasopalatine canal in adults on cone beam computed tomograms: a clinical study and review of the literature. In Vivo. 2015; 29(4): 467-486, indexed in Pubmed: 26130792.

9. Gönül $Y$, Bucak A, Atalay $Y$, et al. MDCT evaluation of nasopalatine canal morphometry and variations: An analysis of 100 patients. Diagn Interv Imaging. 2016; 97(11): 1165-1172, doi: 10.1016/j.diii.2015.11.012, indexed in Pubmed: 26797526.

10. Güncü GN, Yıldırım YD, Yılmaz HG, et al. Is there a gender difference in anatomic features of incisive canal and maxillary environmental bone? Clin Oral Implants Res. 2013; 24(9): 1023-1026, doi: 10.1111/j.16000501.2012.02493.x, indexed in Pubmed: 22587805.

11. Hakbilen S, Magat G. Evaluation of anatomical and morphological characteristics of the nasopalatine canal in a Turkish population by cone beam computed tomography. Folia Morphol. 2018; 77(3): 527-535, doi: 10.5603/ FM.a2018.0013, indexed in Pubmed: 29399754.

12. Jacobs $R$, Lambrichts $I$, Liang $X$, et al. Neurovascularization of the anterior jaw bones revisited using high-resolution magnetic resonance imaging. Oral Surg Oral Med Oral Pathol Oral Radiol Endod. 2007; 103(5): 683-693, doi: 10.1016/j.tripleo.2006.11.014, indexed in Pubmed: 17320428.

13. Keith DA. Phenomenon of mucous retention in the incisive canal. J Oral Surg. 1979; 37(11): 832-834, indexed in Pubmed: 290778.

14. Liang X, Jacobs R, Martens W, et al. Macro- and micro-anatomical, histological and computed tomography scan characterization of the nasopalatine canal. J Clin Periodontol. 2009; 36(7): 598-603, doi: 10.1111/j.1600051X.2009.01429.x, indexed in Pubmed: 19538333.

15. Librizzi ZT, Tadinada AS, Valiyaparambil JV, et al. Cone-beam computed tomography to detect erosions of the temporomandibular joint: Effect of field of view and voxel size on diagnostic efficacy and effective dose. Am J Orthod Dentofacial Orthop. 2011; 140(1): e25-e30, doi: 10.1016/j. ajodo.2011.03.012, indexed in Pubmed: 21724068.

16. Mardinger O, Namani-Sadan N, Chaushu G, et al. Morphologic changes of the nasopalatine canal related to dental implantation: a radiologic study in different de- grees of absorbed maxillae. J Periodontol. 2008; 79(9): 1659-1662, doi: 10.1902/jop.2008.080043, indexed in Pubmed: 18771366.

17. Mraiwa N, Jacobs R, Van Cleynenbreugel J, et al. The nasopalatine canal revisited using $2 \mathrm{D}$ and $3 \mathrm{D} \mathrm{CT}$ imaging. Dentomaxillofac Radiol. 2004; 33(6): 396-402, doi: $10.1259 / \mathrm{dmfr} / 53801969$, indexed in Pubmed: 15665234.

18. Özçakır-Tomruk C, Dölekoğlu S, Özkurt-Kayahan Z, et al. Evaluation of morphology of the nasopalatine canal using cone-beam computed tomography in a subgroup of Turkish adult population. Surg Radiol Anat. 2016; 38(1): 65-70, doi: 10.1007/s00276-015-1520-x, indexed in Pubmed: 26228382.

19. Radlanski RJ, Emmerich S, Renz H. Prenatal morphogenesis of the human incisive canal. Anat Embryol. 2004; 208(4): 265-271, doi: 10.1007/s00429-004-0389-y, indexed in Pubmed: 15293047.

20. Safi Y, Moshfeghi M, Rahimian S, et al. Assessment of nasopalatine canal anatomic variations using cone beam computed tomography in a group of Iranian population. Iran J Radiol. 2016; 14(1), doi: 10.5812/iranjradiol.37028.

21. Sekerci AE, Buyuk SK, Cantekin K. Cone-beam computed tomographic analysis of the morphological characterization of the nasopalatine canal in a pediatric population. Surg Radiol Anat. 2014; 36(9): 925-932, doi: 10.1007/ s00276-014-1271-0, indexed in Pubmed: 24590491.

22. Sicher H. Anatomy and oral pathology. Oral Surgery, Oral Medicine, Oral Pathology. 1962; 15(10): 1264-1269, doi: 10.1016/0030-4220(62)90163-9.

23. Song WC, Jo DI, Lee JY, et al. Microanatomy of the incisive canal using three-dimensional reconstruction of microCT images: an ex vivo study. Oral Surg Oral Med Oral Pathol Oral Radiol Endod. 2009; 108(4): 583-590, doi: 10.1016/j. tripleo.2009.06.036, indexed in Pubmed: 19778745.

24. Stenson N. Stenonis De muscuhs et glandulis. Lugdunum Batavorum (Leyden) -de narium vasis; in Mangeti. Bibl Anatom Genev 1685; 11: 763.

25. Temmerman A, Hertelé S, Teughels W, et al. Are panoramic images reliable in planning sinus augmentation procedures? Clin Oral Implants Res. 2011; 22(2): 189-194, doi: 10.1111/j.1600-0501.2010.02000.x, indexed in Pubmed: 20868452.

26. Thakur AR, Burde K, Guttal K, et al. Anatomy and morphology of the nasopalatine canal using cone-beam computed tomography. Imaging Sci Dent. 2013; 43(4): 273-281, doi: 10.5624/isd.2013.43.4.273, indexed in Pubmed: 24380067.

27. Tlili N, Abdallah S, Amor F, et al. Anatomo-radiological assessment of incisive canal using cone beam computed tomographs. Int J Anat Res. 2017; 5(3.3): 4333-4342, doi: 10.16965/ijar.2017.328.

28. Tözüm TF, Güncü GN, Yıldırım YD, et al. Evaluation of maxillary incisive canal characteristics related to dental implant treatment with computerized tomography: a clinical multicenter study. J Periodontol. 2012; 83(3): 337-343, doi: 10.1902/jop.2011.110326, indexed in Pubmed: 21910596.

29. von Arx T, Lozanoff S. Clinical oral anatomy: a comprehensive review for dental practitioners and researchers. Springer 2016. 